\title{
A well-grounded approach to the mind-body problem
}

Previously published at www.cmaj.ca

\section{The Shaking Woman Or A History of My Nerves}

Siri Hustvedt

Henry Holt and Company; 2010.

$\mathrm{T}$ here is a widely held conviction in medical circles that all can benefit from sharing the diverse fruits of scientific knowledge. Still, the term 'scientific knowledge' covers a lot of conceptual ground, and translating information from specialized branches of science to something most of us can make sense of can be tricky. One of the most enduring conceptual rifts in science has to do with the way we talk about the mind as if it were separate from the body, a division that colours the way doctors perceive their patients and even the way individuals express their suffering. In Siri Hustvedt's latest book, a major literary talent takes a personal journey into the borderland between mind and body, demonstrating dual proficiencies in the languages of neurosciences and psychoanalysis. Readers will be grateful for her efforts.

Two and a half years after her father's death, while giving a talk at the university where he had been a professor,

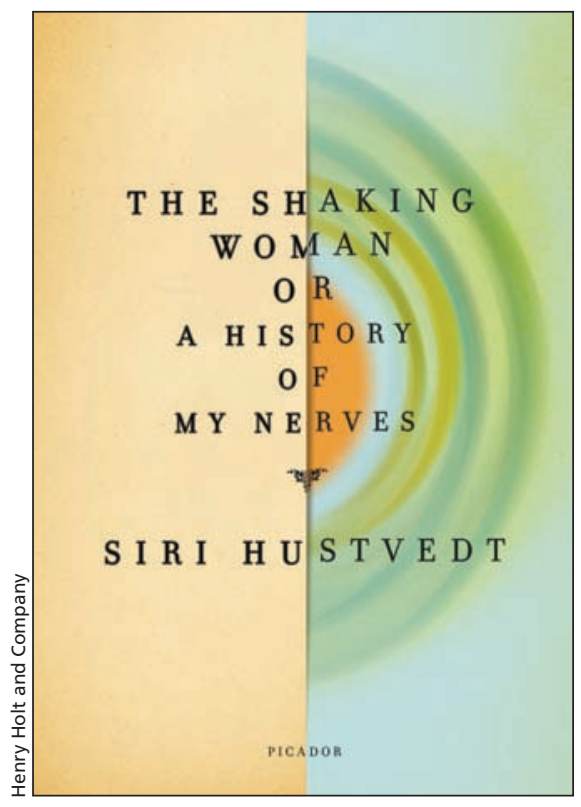

migraine headaches might have implied a need for immediate neurological investigations. Curiously, her initial instinct was to think of a condition that has traditionally been tossed into the bin of psychiatric diagnoses: conversion disorder. She had been researching the scientific literature from both psychiatry and the neurosciences for a novel and it seemed to fit; she had not lost consciousness, the circumstances of the talk were highly emotional and it was plausible that some-

\section{Hustredt shows how scientific facts can be harmonized with the idiosyncrasies of an individual life.}

Hustvedt began to shake uncontrollably on both sides of her body. She did not experience an aura or lose consciousness, and finished her speech without assistance from members of her concerned audience. Was the shaking related to a seizure disorder or was it more closely related to a psychiatric syndrome? Hustvedt's previous history of a shaking spell coupled with her recurrent thing repressed from her consciousness might now be shaking her body. The search to understand her shaking was just beginning and science, it would seem, was now becoming a character in her own life.

Before the diagnosis of conversion disorder congealed in the late 1940s and early 1950 s, its symptoms were covered under the much broader cate- gory of hysteria, which described a range of inexplicable neurological symptoms and amnesia. Sigmund Freud in Studies on Hysteria expressed his frustration with the condition:

"The fact is that local diagnosis and electrical reactions lead nowhere in the study of hysteria, whereas detailed description of mental processes such as we are accustomed to find in the works of imaginative writers enables me ... to obtain at least some kind of insight into the course of that affection."

According to the 19th-century French neurologist Jean Martin Charcot (18251893), hysteria often involved a severe fright, which led patients to use a form of self-hypnosis to keep the painful memory out of their awareness. The philosopher and neurologist, Pierre Janet (1849-1947) was also interested in a relationship between psychic trauma and hysteria. He introduced the word 'dissociation' to describe a division among "systems of ideas and functions that constitute the personality." Janet also introduced the term 'la belle indifference' to refer to a lack of concern about one's own illness, a term now connected specifically to conversion disorder.

In the mid 20th century, the concept of hysteria was parcelled into the somatoform disorders (including conversion disorder) and the dissociative disorders. The somatoform disorders took the unexplained neurological symptoms from hysteria while the dissociative disorders got the cases of unexplained amnesia. As a diagnosis of exclusion, conversion disorder is now surprisingly stable, with fewer than 10 per cent of patients eventually learning of a "physical' explanation for their neurological symptoms. ${ }^{1}$ But what of the 90 per cent for whom no cause can be found? Are they a left-over group of misfits with unresolved issues?

Neuroscientists suggest not: These unresolved issues may be associated with brain scans that look different than most (see illustration on page two). ${ }^{2}$ If 
these observations are eventually generalized (current studies involve very small numbers of patients), how will this change the way people with conversion disorder experience their symptoms? Part of the answer may involve revisiting the question of free will, the extent to which we control not only our broader destinies, but also our immediate physical movements. That we all have some sense of agency is undeniable, but the variability of this experience and its links to observable differences in brain functioning may be greater than philosophers of the past had assumed.

Part of the challenge of translating science is that all abstraction comes at a cost and, in the case of translating the neurosciences to the level of personal experience, that cost can be a reduction of rich life experiences to a few generalizations. For many whose medical problems defy a scientific explanation, healing seems to involve a subtle recalibration of identity, of how an individual remembers her past and how she imagines her future. The Shaking Woman is a deceptively sophisticated approach to the mind-body problem, written in a style similar to Oliver Sacks with a critical slant more characteristic of the philosopher of science, Ian Hacking. It gives us an example of how scientific facts can be harmonized with the idiosyncrasies of an individual life.

By the end of her book, Hustvedt has not found a definitive answer to her shaking. Some treatments have helped, but do not cure, and she comes to accept her condition, to experience herself as The Shaking Woman. Scientific explanation does not have to be the leading character in her life but rather takes its place among several equally important ones.

This is required reading for all medical doctors and for their patients with inexplicable neurological conditions.

\section{Dorian Deshauer MD MSc \\ Associate Editor \\ CMAJ}

\section{REFERENCES}

1. Stone J, Smyth R, Carson A, et al. Systematic review of misdiagnosis of conversion symptoms and "hysteria". BMJ 2005;331:989.

2. Ghaffar O, Staines WR, Feinstein A. Unexplained neurologic symptoms: An fMRI study of sensory conversion disorder. Neurology 2006;67:2036-8.

3. Hacking I. The Social Construction of What? Cambridge (MA): Harvard University Press, 2000.

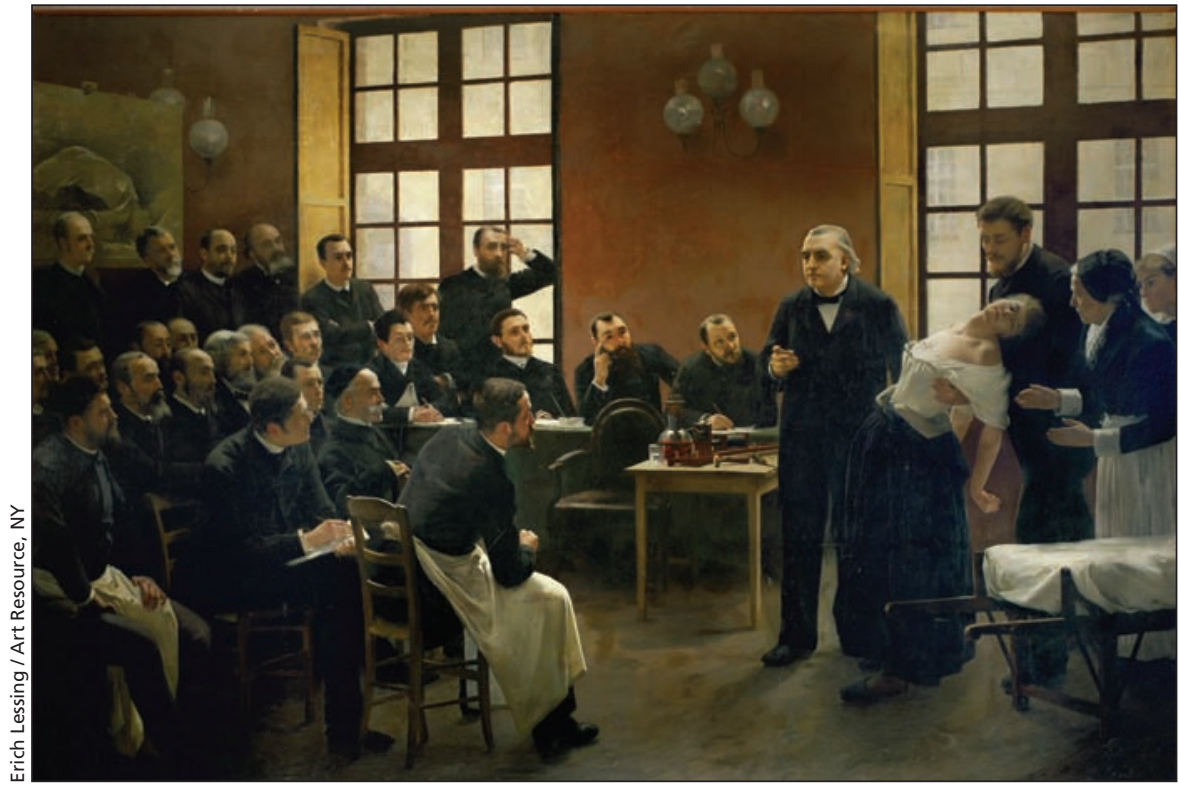

A lesson on hysteria (André Brouillet,1887). This painting, which Sigmund Freud took back with him to Vienna following studies with Jean Martin Charcot, shows Charcot (to the right of the patient), pioneer of neurology at the hospital 'la Salpetriere' in Paris. The patient is Blanche Wittmann, held by Joseph Babinski, who hypnotized her.

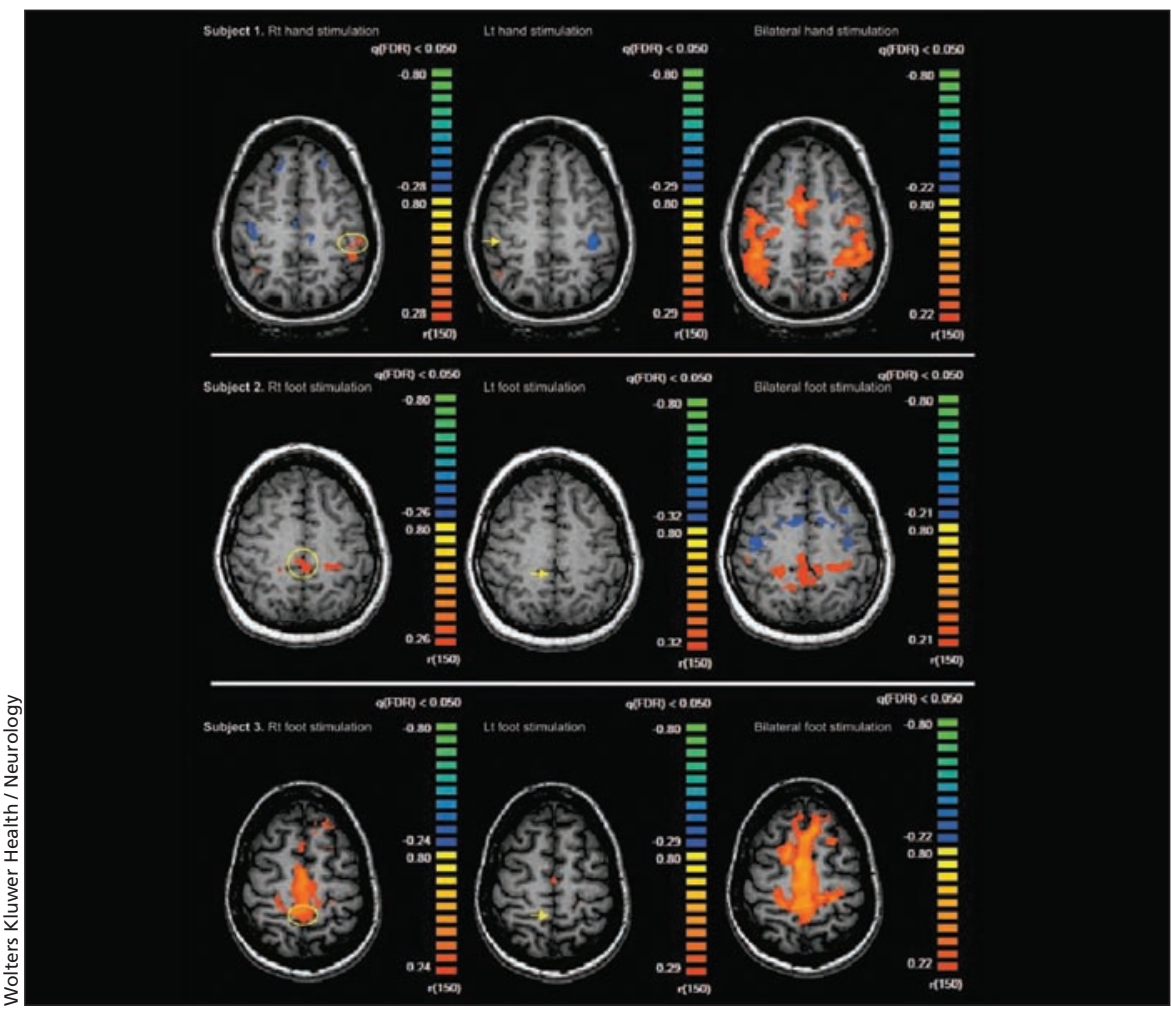

These functional magnetic resonance scans show 3 patients with unilateral sensory conversion disorder. Stimulation of the affected limb does not cause the expected activation of the contralateral S1 brain region (middle column, arrows) while stimulation of the unaffected limb results in the normally expected S1 activation (left column, circle). Bilateral limb stimulation results in the normally observed S1 activation on both sides of the brain (right column). Normal controls are not illustrated here. (from: Ghaffar O, Staines WR, Feinstein A. Unexplained neurologic symptoms: An fMRI study of sensory conversion disorder. Neurology 2006;67:2036-8.) 